\title{
Negatively Charged Cell Membranes-Targeted Highly Selective Chemotherapy with Cationic Hybrid Liposomes against Colorectal Cancer In Vitro and In Vivo
}

Ichihara $\mathrm{H}$, Motomura $\mathrm{M}$ and Matsumoto $\mathrm{Y}^{*}$

Division of Applied Life Science, Graduate School of Engineering, Sojo University, Japan

*Corresponding author: Yoko Matsumoto, Division of Applied Life Science, Graduate School of Engineering, Sojo University, 4-22-1 Ikeda, Nishi-ku, Kumamoto 860-0082, Japan, Tel: +81 96326 3965; Fax: +81 96323 1331; E-mail: matumoto@life.sojo-u.ac.jp

Received date: May 11, 2015; Accepted date: May 23, 2016; Published date: May 26, 2016

Copyright: @ 2016 Ichihara $\mathrm{H}$, et al. This is an open-access article distributed under the terms of the Creative Commons Attribution License, which permits unrestricted use, distribution, and reproduction in any medium, provided the original author and source are credited.

\begin{abstract}
Cationic hybrid liposomes (CHL) composed of $87 \mathrm{~mol} \% \mathrm{~L}$-a-dimyristoylphosphatidylcholine (DMPC), $5 \mathrm{~mol} \%$ polyoxyethylene (21) dodecyl ether $\left(\mathrm{C}_{12}(\mathrm{EO})_{21}\right)$ and 8 mol\% O,O'-ditetradecanoyl-N-(a-trimethylammonioacetyl) diethanolamine chloride $\left(2 \mathrm{C}_{14} \mathrm{ECl}\right)$ were prepared by the method of sonication. A clear solution of $\mathrm{CHL}$ having a hydrodynamic diameter of $100 \mathrm{~nm}$ could be maintained over 4 weeks. The $\mathrm{IC}_{50}$ value of $\mathrm{CHL}$ on the growth of human colorectal cancer (CRC; HCT116) cells was remarkably smaller than that of the DMPC liposomes. Immediate fusion of $\mathrm{CHL}$ including NBDPC into HCT116 cell membranes was confirmed using a confocal laser and total internal reflection fluorescence (TIRF) microscope without affecting normal colon (CCD-33Co) cells. Activation of caspases for apoptosis of HCT116 cells induced by CHL was verified on the basis of fluorescence microscopy. Carcinoma HCT116 cells have lower membrane potential compared to normal CCD-33Co cells, since negatively charged PS and GM1 in HCT116 cells increased compared with that of normal CCD-33Co. Therapeutic effects of $\mathrm{CHL}$ were obtained in xenograft mouse models of CRC in vivo. Induction of apoptosis in tumor of xenograft mouse model of human CRC treated with $\mathrm{CHL}$ was observed in micrographs of tissue section on the basis of TUNEL method. Furthermore, no severe side effects of $\mathrm{CHL}$ were observed in toxicity tests using normal mice.
\end{abstract}

Keywords: Cationic hybrid liposomes; Chemotherapy; Colorectal cancer; Apoptosis; In vivo

\section{Abbreviations}

$\mathrm{C}_{12}(\mathrm{EO})_{21}$ : Polyoxyethylene(21) dodecyl ether; $2 \mathrm{C}_{14} \mathrm{ECl}$ : O,O'ditetradecanoyl-N-(a-trimethylammonioacetyl) diethanolamine chloride; CRC: Colorectal Cancer; DMPC: L- $\alpha-$ dimyristoylphosphatidylcholine; CHL: Cationic Hybrid Liposomes; Composed of DMPC: $\mathrm{C}_{12}(\mathrm{EO})_{21}$ and $2 \mathrm{C}_{14} \mathrm{ECl}$; NBDPC: 1-palmitoyl-2[12-[(7-nitro-2-1,3-benzoxadiazol-4-yl)amino]dodecanoyl]-snglycero-3-phosphocholine;TUNEL: Terminal Deoxynucleotidyl transferase-mediated dUTP-biotin Nick End Labeling

\section{Introduction}

Colorectal cancer (CRC) is one of the most common malignancy occurring in the world. More than one million people worldwide are diagnosed with CRC each year [1]. A multimodal approach with surgical resection and adjuvant therapy is undertaken in CRC treatment. Surgical resection of the tumor is most effective for achieving a complete cure in early stage colorectal cancer. The main combinations of drugs for adjuvant chemotherapy are as follows: 5-fluorouracil (5-FU)/leucovorin (LV) [2], irinotecan/5FU/LV [3], bevacizumab/irinotecan/5-FU/LV [4], FOLFOX (5-FU/ Folinic acid/Oxaliplatin) [5] and FOLFIRI (5-FU/folinic acid/ irinotecan) [6]. Adjuvant chemotherapy may prevent recurrence in patients with CRC in stage III. However, side-effects in combination chemotherapy are much more severe than those in simple chemotherapy. Therefore, the development of a novel treatment without side-effects is desired to improve quality of life of patients.
The lipid components of tumor cell membranes are generally different from those of normal ones [7-9]. Anionic phospholipids are largely absent from the membrane surface of normal cells under normal conditions. The surface exposure of phosphatidylserine (PS) occurs in the outer membrane leaflet from the inner membrane of cancer cells. PS in the outer plasma membrane of tumor cells increase as compared with the normal cells [10-11]. Gangliosides are negatively charged sialic acid-containing glycolsphingo-lipids and overexpress in colon carcinoma [12-14]. Furthermore, negatively charged characteristics of tumor cell membranes could be an important target as a novel chemotherapy treatment from the view point of biophysical characteristics.

We have produced hybrid liposomes (HL) composed of vesicular and micellar molecules [15]. The physical properties of HL such as shape, size, membrane fluidity, and the temperature of phase transition can be controlled by changing the constituents and compositional ratios. Inhibitory effects of HL including antitumor drugs have been observed on the growth of glioma cells in vitro and in vivo [16]. The remarkable inhibitory effects of HL on the growth of various cancer cells were attained in vitro [17-19]. The induction of apoptosis by HL was obtained and the apoptotic pathway was elucidated [20]. Significantly prolonged survival and remarkable suppression of tumor growth were obtained using mice model of carcinoma after the treatment with HL without any drug in vivo [21-23]. No toxicity of HL was observed in normal rats in vivo without any side effects [21-22]. Successful clinical chemotherapy with drug-free HL for patients with lymphoma has been reported after passing the committee of bioethics [22]. DMPC liposomes were unstable and were not suitable for an intravenous injection [16-22]. In addition, cationic hybrid liposomes (CHL) including cationic lipid have been produced by using the sonication method of a mixture of L-a-dimyristoylphosphatidylcholine 
(DMPC), 5 mol\% polyoxyethylene $(21)$ dodecyl ether $\left(\mathrm{C}_{12}(\mathrm{EO})_{21}\right)$ and $8 \quad \mathrm{~mol} \% \quad \mathrm{O}, \mathrm{O}^{\prime}$-ditetradecanoyl-N-( $\alpha$-trimethyl-ammonioacetyl) diethanolamine chloride $\left(2 \mathrm{C}_{14} \mathrm{ECl}\right)$ in a buffer solution [23]. Remarkably inhibitory effects of CHL including cationic lipid on the growth of human renal cell carcinoma (OS-RC-2) cells along with apoptosis in vitro and in vivo have been reported [23]. However, antitumor mechanism of CHL that targeted negatively charged cell membranes have not yet been elucidated.

In this study, we investigated inhibitory effects of CHL composed of $87 \mathrm{~mol} \%$ DMPC, $5 \mathrm{~mol} \% \mathrm{C}_{12}(\mathrm{EO})_{21}$ and $8 \mathrm{~mol} \% 2 \mathrm{C}_{14} \mathrm{ECl}$ on the growth of human colon carcinoma (HCT116) cells that targeted negatively charged cell membranes in vitro and in vivo.

\section{Experimental Section}

\section{Preparation of cationic hybrid liposomes}

CHL were prepared by sonication (VS-N300; VELVO, Tokyo, Japan) of a mixture containing DMPC (purity>99\%; NOF Co. Ltd., Tokyo, Japan), $\mathrm{C}_{12}(\mathrm{EO})_{21}$ (Nikko chemicals Co. Ltd., Tokyo, Japan) and $2 \mathrm{C}_{14} \mathrm{ECl}$ (DC-6-14; Sogo Pharmaceutical Co. Ltd. Tokyo, Japan) using a bath type sonicater in $5 \%$ glucose solution at $45^{\circ} \mathrm{C}$ with $300 \mathrm{~W}$, and filtered with a $0.20 \mu \mathrm{m}$ cellulose acetate filter (Advantec, Tokyo, Japan). Sample solutions were stored at $37^{\circ} \mathrm{C}$.

\section{Dynamic light scattering measurements}

The diameter of CHL was measured with a light scattering spectrometer (Otsuka Electronic, Osaka, Japan) using a He-Ne laser $(633 \mathrm{~nm})$ at a $90^{\circ}$ scattering angle. The diameter $\left(d_{\mathrm{hy}}\right)$ was calculated using the Stokes-Einstein formula $\left(d_{\mathrm{hy}}=\kappa T / 3 \pi \eta D\right)$, where $\kappa$ is the Boltzmann constant, $T$ is the absolute temperature, $\eta$ is the viscosity and $D$ is the diffusion coefficient.

\section{Cell culture}

Human colon carcinoma (HCT116) cell lines were purchased from the American Type Culture Collection (Manassas, VA, USA). HCT116 cells were maintained in RPMI-1640 medium (Gibco, Gaithersburg, $\mathrm{MD}$, USA) supplemented with penicillin $100 \mathrm{U} / \mathrm{mL}$, streptomycin 50 $\mu \mathrm{g} / \mathrm{mL}$, and $10 \%$ fetal bovine serum (HyClone Laboratories, Logan, UT, USA). The cells were cultured in a $5 \% \mathrm{CO}_{2}$ humidified incubator at $37^{\circ} \mathrm{C}$.

The normal colon fibroblast (CCD-33Co) cells were obtained from ATCC (Manassas, VA, USA) and cultured using DMEM medium supplemented with $20 \%$ of fetal bovine serum, $1 \%$ sodium pyruvate $(100 \mathrm{mM}), 1 \%$ non-essential amino acids $(10 \mathrm{mM})$ and $1 \%$ penicillin/ streptomycin solution (Invitrogen, Carlsbad, CA, USA). Cells were maintained at $37^{\circ} \mathrm{C}$ at $5 \% \mathrm{CO}_{2}$ atmosphere.

\section{Assessment of growth inhibition caused by $\mathrm{CHL}$}

The $50 \%$ inhibitory concentration $\left(\mathrm{IC}_{50}\right)$ on the growth of tumor cells was determined on the basis of WST-1 [2-methoxy-4nitrophenyl-3-(4-nitrophenyl)-5-(2,4-disulfophenyl)-2H- tetrazolium, monosodium salt] assay (Cell Counting Kit-1, Dojindo Laboratories, Kumamoto, Japan). Cells $\left(5.0 \times 10^{4}\right.$ cells $\left./ \mathrm{ml}\right)$ were seeded in 96 -well plates and cultured in a $5 \% \mathrm{CO}_{2}$ humidified incubator at $37^{\circ} \mathrm{C}$ for $24 \mathrm{~h}$. Cells were cultured for a further $48 \mathrm{~h}$ after adding DMPC (0.1-5 mM), HL or CHL (0.1-2 mM on the basis of DMPC concentration). WST-1 solution was added and the cells were incubated for $3 \mathrm{~h}$. The absorbance at a wavelength of $450 \mathrm{~nm}$ was measured by spectrophotometer (Emax; Molecular Devices Co., California, USA). The inhibitory effects of CHL on the growth of tumor cells were evaluated by Amean/Acontrol, where Amean and Acontrol denote the absorbance of water-soluble formazan, in the presence and absence of CHL, respectively.

\section{Fusion and accumulation of $\mathrm{CHL}$ into the cell membrane}

The fusion and accumulation of CHL including a fluorescence probe (1-palmitoyl-2-[12-[(7-nitro-2-1,3-benzoxadiazol-4-yl) amino] dodecanoyl]-sn-glycero-3- phosphocholine (NBDPC; Avanti Polar Lipids, Alabama, U.S.A.) into the membrane of HCT-116 and CCD-33Co cells was performed using confocal laser microscope (TCSSP; Leica Microsystems, Berlin, Germany). Cells $\left(2.0 \times 10^{5}\right.$ cells $\left./ \mathrm{mL}\right)$ were cultured in a $5 \% \mathrm{CO}_{2}$ humidified incubator at $37^{\circ} \mathrm{C}$ for $24 \mathrm{~h}$. The cells were treated with CHL $\left([\mathrm{DMPC}]=0.45 \mathrm{mM},\left[\mathrm{C}_{12}(\mathrm{EO})_{21}\right]=0.027\right.$ $\left.\mathrm{mM}, \quad\left[2 \mathrm{C}_{14} \mathrm{ECl}\right]=0.044 \mathrm{mM}, \quad[\mathrm{NBDPC}] \quad 0.022 \mathrm{mM}\right)$ including fluorescence-labeled lipid for $4 \mathrm{~h}$ and were observed using confocal laser microscope with a $488 \mathrm{~nm}$ Ar laser line (detection at 505-555 $\mathrm{nm})$.

We used CHL including NBDPC ([DMPC $]=0.45 \mathrm{mM}$, $\left.\left[\mathrm{C}_{12}(\mathrm{EO})_{21}\right]=0.027 \mathrm{mM},\left[2 \mathrm{C}_{14} \mathrm{ECl}\right]=0.044 \mathrm{mM},[\mathrm{NBDPC}]=0.022 \mathrm{mM}\right)$ ) for total internal reflection fluorescence (TIRF) microscopy. TIRF images were captured every 3 seconds with a cooled CCD camera (EM-CCD, Hamamatsu Photonics) and the fluorescent intensity was measured with a software (Aquacosmos, Hamamatsu Photonics, Hamamatsu, Japan).

\section{Caspase fluorometric protease assay}

The caspase activity was measured as the protease activity of caspase using the cell-permeable substrate of PhiPhiLux G1D2 (caspase-3), CaspaLux 8-L1D2 (caspase-8) and CaspaLux 9-M1D2 (caspase-9) (OncoImmunin, Inc., Gaithersburg, MD, USA) using a confocal laser microscope according to the manufacturer's instructions. HCT116 cells $\left(6.0 \times 10^{6}\right.$ cells) were treated with $\mathrm{CHL}$ ([DMPC] $=11.5 \mathrm{mM}$, $\left.\left[\mathrm{C}_{12}(\mathrm{EO})_{21}\right]=0.66 \mathrm{mM},\left[2 \mathrm{C}_{14} \mathrm{ECl}\right]=1.06 \mathrm{mM}\right)$ for $1-48 \mathrm{~h}$. The cells were centrifuged at $3000 \mathrm{rpm}$ for $5 \mathrm{~min}$, and resuspended in $50 \mu \mathrm{l}$ of chilled cell lysis buffer. The cell lysates were incubated with reaction buffer (50 $\mu \mathrm{l})$ and respective caspase substrate $(75 \mu \mathrm{l})$ at $37^{\circ} \mathrm{C}$ for $1 \mathrm{~h}$. After washing twice with $1 \mathrm{ml}$ of ice-cold PBS (-), the cells were resuspended in $1 \mathrm{ml}$ PBS (-). The stained-cells were observed using confocal laser microscope with excitation $488 \mathrm{~nm}$ of $15 \mathrm{~mW}$ Ar laser (detection at 505-555 nm).

\section{Fluorescence analysis of phosphatidylserine (PS) in plasma membranes of tumor cells}

The amount of PS in the plasma membranes of tumor cells was analyzed using Annexin- $\mathrm{V}$ binding assay [24]. After the preincubation of tumor cells $\left(2.0 \times 10^{4}\right.$ viable cells $\left./ \mathrm{ml}\right)$ in a humidified atmosphere of $5 \% \mathrm{CO}_{2}$ at $37^{\circ} \mathrm{C}$ for $96 \mathrm{~h}$, the tumor cells were processed for an Annexin-V-FLUOS Staining Kit (Roche Diagnostics, Basel, Switzerland) according to the manufacturer's instruction. The stained cells were analyzed using a flow cytometer with a single excitation 488 $\mathrm{nm}$ of $15 \mathrm{~mW}$ air-cooling Ar laser. The relative amounts of PS in the outer plasma membranes were quantitatively determined from the Annexin-V signal intensity detected by FL1 sensor in $515-530 \mathrm{~nm}$. 


\section{Fluorescence analysis of ganglioside (GM1) in plasma membranes of tumor cells}

The amount of GM1 in the plasma membranes of tumor cells was observed using a confocal laser microscope with a fluorescent reagent cholera toxin subunit B (CTB) conjugates Alexa Fluor 647 (Invitrogen, Carlsbad, CA, USA) [25]. After the pre-culture of HCT116 cells $(2.0 \times$ $10^{4}$ viable cells $/ \mathrm{ml}$ ) in a humidified atmosphere of $5 \% \mathrm{CO}_{2}$ at $37^{\circ} \mathrm{C}$ for $24 \mathrm{~h}$, the cells were washed with phosphate buffered saline (PBS (-)) and incubated in the culture media for $60 \mathrm{~min}$. Subsequently, the cells were washed with PBS (-), incubated in the culture media containing $30 \mathrm{~m} \mathrm{~g} / \mathrm{ml} \mathrm{CTB}$ for $30 \mathrm{~min}$ on ice, and observed using a confocal laser microscope with a He-Ne laser (excitation/detection $633 \mathrm{~nm} / 650-670$ $\mathrm{nm})$.

\section{Zeta potential of $\mathrm{CHL}$ and tumor cells}

Zeta potential of the nanoparticles (DMPC, HL and CHL) and cells (HCT116 and CCD-33Co) was measured using a zeta potential spectrophotometer (ELS-8000; Otsuka Electronics Co. Ltd., Osaka, Japan) [26-27]. All measurements were made at $\mathrm{pH} 7$ to simulate mascara application. The samples were diluted 1,000-fold in $0.1 \mathrm{M}$ $\mathrm{NaCl}$ solution or deionized water for the measurement of zeta potential, and washed 5 min prior to measurement. The measurements were repeated three times.

\section{Hemolysis assay and fusion observation to erythrocytes of CHL}

To study the interaction of CHL with the negatively charged erythrocytes, we performed the hemolysis assay at increasing phospholipid concentration [28]. Blood was collected from an adult rat into tubes containing EDTA solution and centrifuged at $2000 \mathrm{rpm}$ for $10 \mathrm{~min}$. The pelleted erythrocytes were washed three times with PBS (-), $\mathrm{pH}$ 7.4. The erythrocyte count was determined using a hemocytometer. CHL, at different concentrations in PBS, were added to pre-determined number of erythrocytes and incubated at $37^{\circ} \mathrm{C}$ for $2 \mathrm{~h}$. The samples were centrifuged at $2000 \mathrm{rpm}$ for $10 \mathrm{~min}$ and absorbance (A) of the supernatant was analyzed at $560 \mathrm{~nm}$ by spectrophotometric analysis. Triton $\mathrm{X}-100$ and PBS treated erythrocytes were used as controls for $100 \%$ and $0 \%$ hemolysis, respectively. Fusion of CHL including a fluorescence probe (1palmitoyl-2-[12-[(7-nitro-2-1,3-benzoxadiazol-4-yl)amino]dodecanoyl]-sn-glycero-3-phospho choline (NBDPC; Avanti Polar Lipids, Alabama, U.S.A.) to erythrocytes was observed using a confocal laser microscope with a He-Ne laser (excitation/detection $633 \mathrm{~nm} /$ 650-670 nm).

\section{Assessment of antitumor activity in vivo}

The animals were handled in accordance with the guidelines for animal experimentation of Japanese law during the study. This study was carried out in strict accordance with the recommendations in the Guide for the Care and Use of Laboratory Animals of the Sojo University. The protocol was approved by the Committee on the Ethics of Animal Experiments of the Sojo University. Female nude mice (BALB/cA Jcl-nu/nu) were obtained from CLEA Japan, Inc (Tokyo, Japan). HCT116 cells $\left(5.0 \times 10^{6}\right.$ cells $)$ suspended into matrigel (BD Co., NJ, USA) were subcutaneously inoculated to dorsal of mice. Number of mice was five in each group. The tumor volume reached $100-300 \mathrm{~mm}^{3}$ at day 7 after the inoculation of HCT116 cells, and then CHL were intravenously administered once each day for 14 days from day 7. The tumor volume was measured using Vernier caliper and calculated using the equation of $\mathrm{V}=0.5 \times \mathrm{a}^{2} \times \mathrm{b}$, where $\mathrm{a}$ and $\mathrm{b}$ denote the smallest and longest superficial diameter, respectively [29]. Reduction rate of tumor volume was calculated using the equation of $\{1$-(median tumor volume of treated group / median tumor volume of control group) $\times 100\}$.

\section{Tunel method}

Detection of apoptotic cells was performed on the basis of TUNEL method using an in situ apoptosis detection kit (ApopTag Plus Peroxidase, Intergen, MA, USA) according to manufacturer's directions. HCT116 cells $\left(5.0 \times 10^{6}\right.$ cells $)$ suspended into matrigel were subcutaneously inoculated to dorsal of $\mathrm{Balb} / \mathrm{c}-\mathrm{R} / \mathrm{J}$ mice. CHL was administered into the caudal vein of mice once each for 14 days after the HCT116 cells were inoculated to mice. All surgery was performed under anesthesia using sodium pentobarbital and Ketamine, and all efforts were made to minimize suffering. Tumor was removed from anaesthetized mice after the treated with $\mathrm{CHL}$ and fixed in $10 \%$ formalin solution. Paraffin-embedded sections were made, and the cell death observation of a solid tumor was performed on the basis of TUNEL assay according to the conventional method.

\section{Assessment of toxicity in vivo}

Female mice $(\mathrm{BALB} / \mathrm{cA} \mathrm{Jcl})$ were obtained from CLEA Japan, Inc. The animals were handled in accordance with the guidelines for animal experimentation of Japanese law during the study. This study was carried out in strict accordance with the recommendations in the Guide for the Care and Use of Laboratory Animals of the Sojo University. The protocol was approved by the Committee on the Ethics of Animal Experiments of the Sojo University. The mice were randomly grouped on the basis of the body weight using the stratified randomization method. Number of mice was three in each group. CHL were intravenously administered into the caudal vein of mice once each day for 2 weeks. The mice were weighed during the experimental period. The blood was collected from the heart in mice under anesthesia using sodium pentobarbital and Ketamine, and all efforts were made to minimize suffering. White blood cells (WBC), red blood cells (RBC), hemoglobin (Hgb) and hematocrit (HCT) were counted using multiple automatic blood cell county device (F-500, Sysmex Co., Hyogo, Japan). Glutamic oxaloacetic transaminase (GOT), glutamic pyruvate transaminase (GPT), blood urea nitrogen (BUN) and creatinine (CRE) were measured using dry chemistry systems (DRICHEM 3500V, FUJIFILM Co. Ltd., Tokyo, Japan). Organs (heart, lung, liver, spleen and kidney) were weighed after anatomizing the mice.

\section{Pharmacokinetics}

Pharmacokinetics of CHL including a fluorescence probe, NBDPC, was performed using female $\mathrm{BALB} / \mathrm{cA}$ mice. The mice were randomly grouped on the basis of body weight by the stratified randomization method. CHL including NBDPC were intravenously administered to mice. The tissues were resected from the mice under anesthesia using sodium pentobarbital and Ketamine, and embedded directly in optimum cutting temperature (OCT) compound (Sakura Finetek, Tokyo, Japan) at room temperature. The OCT-embedded tissues were rapidly frozen in hexane/dry ice at $-20^{\circ} \mathrm{C}$, and then the frozen tissue blocks were cut into $5 \mu \mathrm{m}$ sections using a freezing microtome (Leica CM1850, Wetzlar, Germany). The cryosection of the tissues were observed by confocal microscope (Leica TCS-SP, Heidelberg, 
Citation: Ichihara H, Motomura M, Matsumoto Y (2016) Negatively Charged Cell Membranes-Targeted Highly Selective Chemotherapy with Cationic Hybrid Liposomes against Colorectal Cancer In Vitro and In Vivo. J Carcinog Mutagen 7: 267. doi:10.4172/2157-2518.1000267

Page 4 of 8

Germany) using a $488 \mathrm{~nm}$ Ar laser (detection, NBD: 515-555 nm, Alexa Fluor 594: 560-620 nm).

\section{Statistical analysis}

Results are presented as mean \pm S.D. Data were statistically analyzed using Student's t-test. A $p$ value of less than 0.05 was considered to represent a statistically significant difference.

\section{Results and Discussion}

\section{Physical properties of $\mathrm{CHL}$}

The physical properties of CHL composed of $87 \mathrm{~mol} \%$ DMPC, 5 mol $\% \mathrm{C}_{12}(\mathrm{EO})_{21}$, and $8 \mathrm{~mol} \% 2 \mathrm{C}_{14} \mathrm{ECl}$ were examined. The diameter of $\mathrm{CHL}$ was measured by dynamic light scattering measurement and electron microscope. The mean $d_{\text {hy }}$ of CHL were $100 \mathrm{~nm}$, which remained stable for more than one month at $37^{\circ} \mathrm{C}$. On the other hand, DMPC liposomes were unstable and precipitated after 28 days.HL (95 mol\% DMPC/5 mol\% $\left.\mathrm{C}_{12}(\mathrm{EO})_{21}\right)$ were gradually increased $(>400 \mathrm{~nm})$ with time. These results suggest the CHL having a diameter of $100 \mathrm{~nm}$ should be appropriate for in vivo and clinical applications due to avoiding reticularendothelial systems when they are intravenously injected.

\section{Inhibitory effects of CHL on the growth of HCT116 cells}

We examined the fifty percent inhibitory concentration $\left(\mathrm{IC}_{50}\right)$ of $\mathrm{CHL}$ on the growth of human colon carcinoma (HCT116) cells using WST-1 assay in vitro (Figure 1 ). The $\mathrm{IC}_{50}$ values of $\mathrm{CHL}$ against HCT116 cells were much smaller than those of the DMPC liposomes and HL. On the other hand, $\mathrm{IC}_{50}$ values for human normal colon (CCD-33Co) cells were much larger than those for tumor cells after the treatment with DMPC liposomes, HL, and CHL (Figure 1). The $\mathrm{IC}_{50}$ values of HL and CHL for CCD-33Co cells were approximately two and four times higher than those for HCT116 cells, respectively. It is noteworthy that high inhibitory effects of CHL for human colon carcinoma (HCT116) cells were obtained without affecting the growth of normal human colon (CCD-33Co) cells.

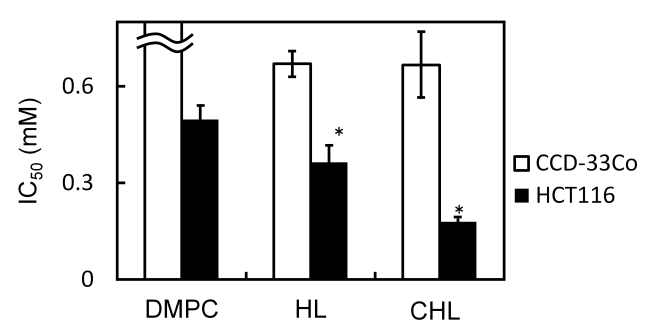

Figure 1: Inhibitory effects of cationic HL on the growth of human colon carcinoma (HCT116) cells. Cationic HL Inhibited the growth of human colon carcinoma (HCT116) cells without affecting the growth of normal human colon (CCD-33Co) cells.

\section{Fusion and accumulation of $\mathrm{CHL}$ into cell membranes of CRC}

We examined fusion and accumulation of CHL including NBDPC as a fluorescence probe into HCT116 cell membrane using a confocal

laser scanning microscope (Figure 2). Remarkable accumulation of CHL including NBDPC into HCT116 cell membrane were observed for $3.5 \mathrm{~h}$, although less accumulation of HL was obtained. On the other hand, little accumulation was detected in the case of DMPC liposomes. In contrast, no accumulation of CHL and HL for normal colon CCD-33Co cells were observed (Figure 2). It is also worthy to note that CHL distinguished between colon carcinoma HCT116 and normal colon CCD-33Co cells. Next, we examined the fusion of CHL into HCT116 cell membrane using total internal reflection fluorescence (TIRF) microscope. TIRF micrographs of HCT116 cell after the treatment with CHL including NBDPC (Figure 2). Fluorescence intensity of NBDPC incorporated into CHL into HCT116 cell was measured (Figure 2). Interestingly, the fluorescence intensity of NBDPC incorporated into CHL in HCT116 cell membrane drastically increased after $10 \mathrm{~min}$ (Figures $2 \mathrm{~B}$ and $2 \mathrm{C}$ ). These results suggest that CHL could selectively fuse and accumulate into HCT116 cell membranes.

(A)
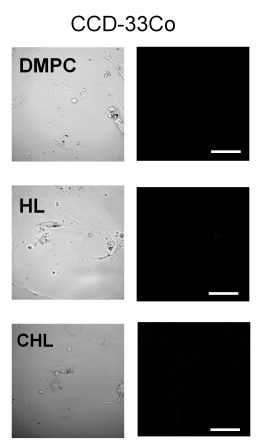

(B)

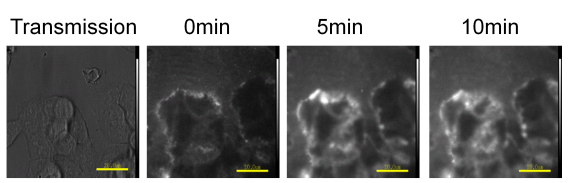

(C)

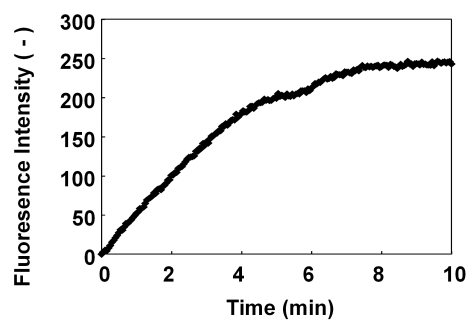

Figure 2: (A) CHL including NBDPC selectively fuse and accumulate into the plasma membranes of HCT-116 cells for 3.5h. Scale bar, $60 \mu \mathrm{m}$. [DMPC] $=0.45 \mathrm{mM},\left[\mathrm{C}_{12}(\mathrm{EO})_{21}\right]=0.027 \mathrm{mM}$, $\left[2 \mathrm{C}_{14} \mathrm{ECl}\right]=0.044 \mathrm{mM},[\mathrm{NBDPC}]=0.022 \mathrm{mM}$. (B) TIRF images of human colon carcinoma (HCT116) cells and normal colon (CCD-33Co) cells treated with CHL including NBDPC. Scale bar, $20 \mu \mathrm{m}$. [DMPC $]=0.18 \mathrm{mM},\left[\mathrm{C}_{12}(\mathrm{EO})_{21}\right]=0.011 \mathrm{mM},\left[2 \mathrm{C}_{14} \mathrm{ECl}\right]=$ $0.017 \mathrm{mM},[\mathrm{NBDPC}]=0.009 \mathrm{mM}$.(C) Time course of meanfluorescent intensity of NBDPC embedded into the cell membranes of HCT-116 cells. 
Citation: Ichihara H, Motomura M, Matsumoto Y (2016) Negatively Charged Cell Membranes-Targeted Highly Selective Chemotherapy with Cationic Hybrid Liposomes against Colorectal Cancer In Vitro and In Vivo. J Carcinog Mutagen 7: 267. doi:10.4172/2157-2518.1000267

Page 5 of 8

\section{Activation of caspases by $\mathrm{CHL}$}

Activation of caspases is an indispensable process in the execution phase of apoptosis. To investigate the apoptotic pathways of HCT116 cells induced by CHL, the activation of caspase- 8 , caspase- 9 and caspase-3 were examined using the cell-permeable fluorescence substrate. Fluorescence micrographs of HCT116 cells stained with the cell-permeable fluorescence caspase-8, caspase- 9 and caspase- 3 substrate after the treatment with CHL are shown in Figure 3. The caspase-3, 8, and 9 activity in HCT116 cells were observed after the treatment with CHL for $1 \mathrm{~h}$. These results suggest that the activation of caspase-3, 8, and 9 could be implicated in the apoptosis induced by CHL for HCT116 cells.

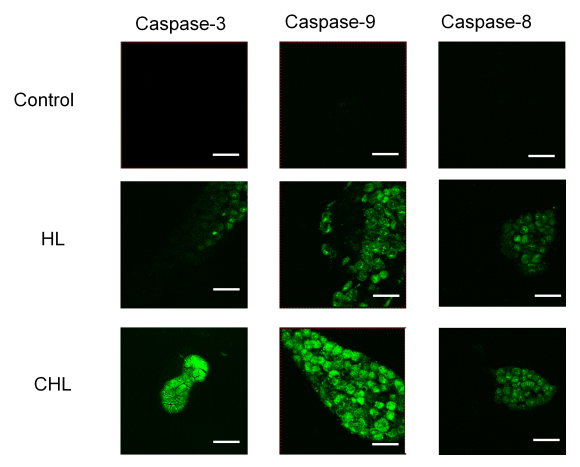

Figure 3: Activation of caspase-3, caspase-8, caspase-9 in human colon carcinoma (HCT116) cells after the treatment with CHL for 1 h.

CHL induced apoptosis for HCT116 cells through mitochondria and the activation of caspase-8, 9 and 3. [DMPC] $=11.5 \mathrm{mM}$, $\left[\mathrm{C}_{12}(\mathrm{EO})_{21}\right]=0.66 \mathrm{mM},\left[2 \mathrm{C}_{14} \mathrm{ECl}\right]=0.106 \mathrm{mM}$. Scale bar, $50 \mu \mathrm{m}$.

\section{Membrane potential properties of HCT116}

The surface exposure of PS occurred in the outer membrane leaflet of cancer cells. PS in the outer plasma membrane of tumor cells increased as compared with the normal cells [10-11]. Surface density of negatively charged PS in the outer membrane of cancer cells was evaluated to determine surface negative charge density of various cancer cells. PS in the outer membrane was stained with Annexin VFITC and detected by flow cytometry. The results are shown in Figure 4A. Relative fluorescence intensity of Annexin V-FITC for HCT116 cell membranes was two times higher than that for CCD-33Co cells. Cancer cell membranes have significantly more content of gangliosides (GM1) including sialic acid residues as compared with normal ones [12-14]. Next, we measured GM1 stained with fluorescence CTB in HCT116 cell membranes using flow cytometer. The results are shown in Figure 4B. Relative fluorescence intensity of CTB for HCT116 cells treated with CHL was two times that for CCD-33Co cells. Cancer cells have lower membrane potential compared to normal cells [27]. Zeta potential in HCT116 cells was evaluated to determine electrostatic interactions between membrane of HCT116 cells and CHL (Figure 4). Zeta potential in HCT116 cells was much lower than that in CCD-33Co cells. These results indicate that CHL selectively inhibit the growth of HCT116 cells having negatively charged cell membranes.
(A)

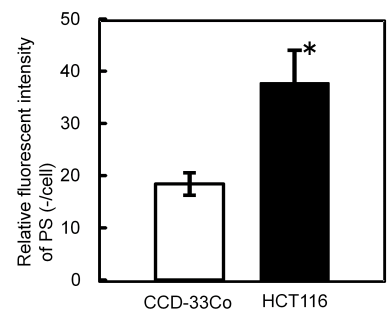

(B)

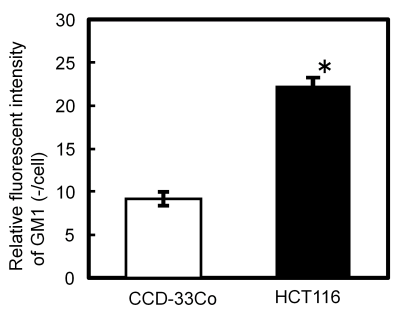

(C)

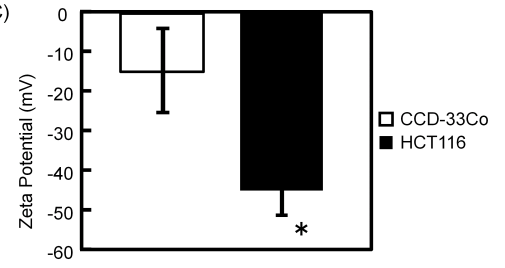

Figure 4: (A) Relative fluorescent intensity of PS for CCD-33Co and HCT116 cells. ${ }^{*} p<0.05$ (vs. CCD-33Co cells.) (B) Relative fluorescent intensity of GM1 for CCD-33Co and HCT116 cells. ${ }^{\star} p<0.05$ (vs. CCD-33Co cells. (C) Zeta Potential for CCD-33Co and HCT116 cells. ${ }^{\star} p<0.05$ (vs. CCD-33Co cells.)

\section{Hemolysis measurements of $\mathrm{CHL}$ in vitro}

There is the problem of potential hemolysis by conventional liposomal drugs [30,31]. We examined fusion of CHL including $\mathrm{NBDPC}$ as a fluorescence probe into hemocyte of normal rats using a confocal laser scanning microscope in vitro (Figure 5A). No accumulation of DMPC, HL and CHL for normal hemocyte of rats were observed. Hemolysis test of CHL was performed using the blood of normal rats in vitro (Figure 5). Few hemolysis was observed in red blood cells after the treatment with HL and CHL. On the other hand, hemolysis in the red blood cells treated with DMPC liposomes increased in a dose dependent manner. Hemolysis of DMPC singlecomponent liposome for RBC has been reported [31]. These results indicate that CHL should not cause hemolysis for the red blood cells.

\section{Therapeutic effects of CHL for xenograft mice of CRC in vivo}

We examined therapeutic effects of intravenous treatment with CHL on the growth of tumor in subcutaneous xenograft model mice of CRC (Figure 6). The remarkable reduction rate of $80 \%(p<0.05)$ in tumor volume was obtained in xenograft mice treated with CHL, in contrast with that of $45 \%$ in xenograft mice treated with HL and DMPC liposomes (Figure 6A and 6B). It is noteworthy that remarkable reduction of tumor volume was obtained in xenograft model mice of CRC intravenously treated with CHL without drugs after subcutaneously inoculating HCT116 cells. 
Citation: Ichihara H, Motomura M, Matsumoto Y (2016) Negatively Charged Cell Membranes-Targeted Highly Selective Chemotherapy with Cationic Hybrid Liposomes against Colorectal Cancer In Vitro and In Vivo. J Carcinog Mutagen 7: 267. doi:10.4172/2157-2518.1000267

Page 6 of 8

(A)

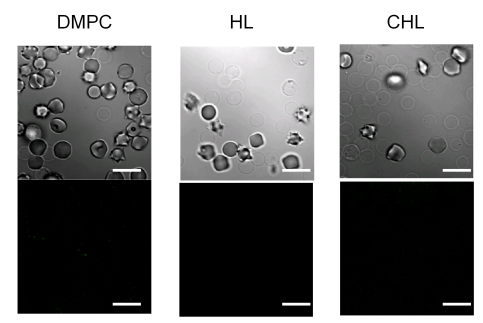

(B)

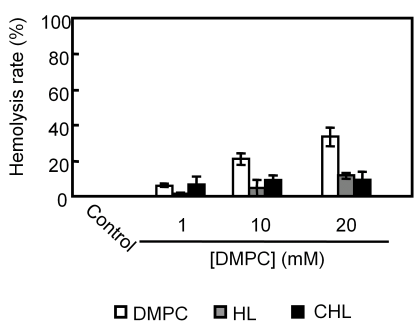

Figure 5: (A) No accumulation of CHL including NBDPC into the plasma membranes of normal hemocyte of rats. Scale bar, $50 \mu \mathrm{m}$. (B) Hemolysis rate of red blood cells treated with CHL for $2 \mathrm{~h}$. Few hemolysis was observed in red blood cells after the treatment with HL and CHL. Increased hemolysis in the red blood cells treated with DMPC liposomes was observed. Data represent the mean \pm S.D.

\section{Induction of apoptosis by $\mathrm{CHL}$ in vivo}

We examined the induction of apoptosis by CHL for solid tumor in xenograft model mice of CRC treated with CHL using TUNEL method (Figure 6C).

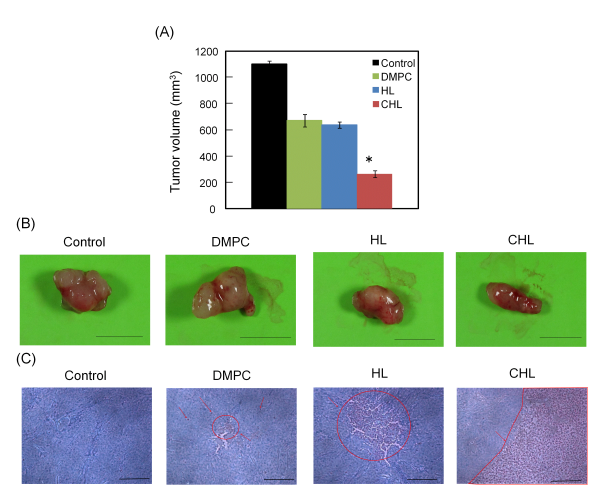

Figure 6: (A) Tumor volume changes in xenograft mouse models of colon carcinoma treated with CHL after the inoculation of HCT116 cells. ${ }^{\star} p<0.05$ ( vs. Control.) (B) Suppression of the tumor growth by CHL in xenograft mouse models of colon carcinoma. Scale bar: 1 $\mathrm{cm}$ (C) Induction of apoptosis in the tissue section of tumor in xenograft mouse models of colon carcinoma after the treatment with CHL. Scale bar: $0.5 \mathrm{~mm}$.

Numerous of apoptotic cells were observed in the tumor cells of tissue section in xenograft mice after the treatment with CHL. Many apoptotic cells in tissue section in xenograft mice treated with CHL were observed. Few apoptotic cells were observed in the group treated with DMPC liposomes. These results indicate that CHL are remarkably effective for inhibiting the growth of HCT116 cells along with apoptosis using xenograft model mice of CRC in vivo.

\section{Toxicity and pharmacokinetics of $\mathrm{CHL}$ in vivo}

Assessment of the chronic toxicity of CHL was carried out using normal healthy mice after the injection of CHL for two weeks. No sideeffects of HL composed of DMPC and $\mathrm{C}_{12}(\mathrm{EO})_{21}$ on normal rats for 6 months have been reported [23]. No weight loss was observed in the mice treated with CHL, as shown in Figure 7A. The number of red and white blood cells of mice treated with CHL were almost the same as those of normal mice (Figure 7B). Remarkable abnormal findings in mice treated intravenously with CHL were not observed, suggesting that CHL have no severe side effects in hematological tests (Figure 7B). In addition, all of the other biochemical parameters, such as ALP, GOT and GPT activities, as well as levels of albumin, urea nitrogen, creatinine, glucose, total protein, calcium, inorganic phosphorus, sodium, potassium and chloride, were not significantly different from those observed in the control groups (data not shown). The biodistribution of NBDPC-labeled CHL was traced using fluorescence micrographs of the tissue section of various organs at different time points (Figure 8). Quantitative estimation in distribution of CHL showed maximum fluorescent intensity (approximately 20) in the liver, $2 \mathrm{~h}$ post intravenous injection. On the other hand, maximum fluorescence intensity after the intravenous injection of HL and DMPC were about 40 and 70 , respectively (data not shown). The accumulation of CHL in liver was less as compared to HL and DMPC liposomes. Furthermore, no accumulation of $\mathrm{CHL}$ in various organs such as kidney, lung and spleen was observed. CHL did not show any side effects within the tested parameters. These results indicate that CHL should have no severe side-effects in vivo.

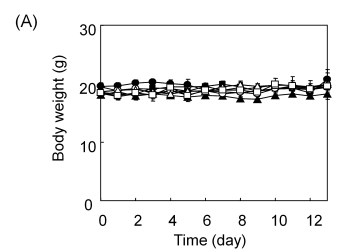

(B)

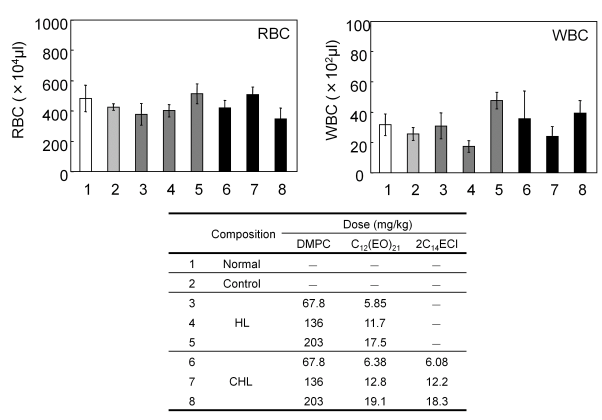

Figure 7: (A) Body weight change for normal mice after the intravenous administration of CHL for two weeks. Data represent the mean S.D. (B) Hematological findings for normal mice after the intravenous administration of CHL for two weeks. 


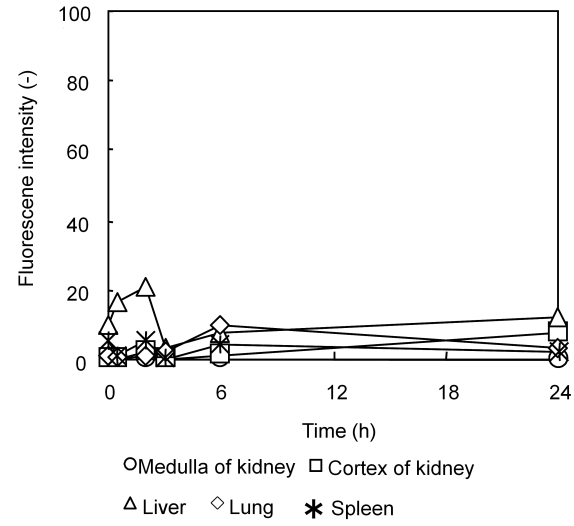

Figure 8: Fluorescence intensity of NBDPC incorporated into CHL in various organ of normal mice after the intravenous administration of CHL including NBDPC. Dose for DMPC: 67.8 $\mathrm{mg} / \mathrm{kg}$.

\section{Conclusion}

We clearly demonstrated that therapeutic effects of CHL on model mice of human CRC along with apoptosis were obtained. The noteworthy aspects in this study are as follows:

(a) The $\mathrm{IC}_{50}$ value of $\mathrm{CHL}$ on the growth of HCT116 cells were remarkably smaller than that of the DMPC liposomes. (b) Immediate fusion of CHL including NBDPC into HCT116 cell membranes was confirmed using a confocal laser and total internal reflection fluorescence (TIRF) microscope without affecting normal colon (CCD-33Co). (c) Activation of caspases for apoptosis of HCT116 cells induced by CHL was verified on the basis of fluorescence microscopy. (d) Carcinoma HCT116 cells have lower membrane potential compared to normal CCD-33Co cells, since negatively charged PS and GM1 in HCT116 cells increased compared with that of normal CCD-33Co. (e) Therapeutic effects of CHL were obtained in xenograft mouse models of colon carcinoma in vivo. (f) Induction of apoptosis in tissue section of tumor in xenograft mouse models of CRC treated with CHL was observed in vivo. (g) No severe side effects of CHL using normal mice were observed on the basis of hemolysis, toxicity, and biodistribution tests. The results in this study could be advantageous of CHL in the novel chemotherapy with a little side effects to substitute for the conventional combination chemotherapy for patients with colon cancer in future clinical applications.

\section{Acknowledgement}

We thank Motoki Hino and Masayo Umebayashi for technical assistance. This work was supported in part by a Grant-in Aid for Science Research from the Ministry of Education, Science, and Culture of Japan (No. 25420843, 25289299).

\section{References}

1. Torre LA, Bray F, Siegel RL, Ferlay J, Lortet-Tieulent J, et al. (2015) Global cancer statistics, 2012. CA Cancer J Clin 65: 87-108.

2. O'Connell MJ, Mailliard JA, Kahn MJ, Macdonald JS, Haller DG, et al. (1997) Controlled trial of fluorouracil and low-dose leucovorin given for
6 months as postoperative adjuvant therapy for colon cancer. J Clin Oncol 15: $246-250$.

3. Saltz LB, Douillard JY, Pirotta N, Alakl M, Gruia G, et al. (2001) Irinotecan plus fluorouracil/leucovorin for metastatic colorectal cancer: a new survival standard. Oncologist 6: 81-91.

4. Hurwitz H, Fehrenbacher L, Novotny W, Cartwright T, Hainsworth J, et al. (2004) Bevacizumab plus irinotecan, fluorouracil, and leucovorin for metastatic colorectal cancer. N Engl J Med 350: 2335-2342.

5. Bokemeyer C, Bondarenko I, Hartmann JT, de Braud F, Schuch G, et al. (2011) Efficacy according to biomarker status of cetuximab plus FOLFOX-4 as first-line treatment for metastatic colorectal cancer: the OPUS study. Ann Oncol 22: 1535-1546.

6. Peeters M, Strickland AH, Lichinitser M, Suresh AV, Manikhas G, et al. (2013) A randomised, double-blind, placebo-controlled phase 2 study of trebananib (AMG 386) in combination with FOLFIRI in patients with previously treated metastatic colorectal carcinoma. Br J Cancer 108: 503-511.

7. Van Blitterswijk WJ, De Veer G, Krol JH, Emmelot P (1982) Comparative lipid analysis of purified plasma membranes and shed extracellular membrane vesicles from normal murine thymocytes and leukemic GRSL cells. Biochim Biophys Acta 688: 495-504.

8. Shinitzky M (1984) Membrane fluidity in malignancy. Adversative and recuperative. Biochim Biophys Acta 738: 251-261.

9. Hendrich AB, Michalak K (2003) Lipids as a target for drugs modulating multidrug resistance of cancer cells. Curr Drug Targets 4: 23-30.

10. Utsugi T, Schroit AJ, Connor J, Bucana CD, Fidler IJ (1991) Elevated expression of phosphatidylserine in the outer membrane leaflet of human tumor cells and recognition by activated human blood monocytes. Cancer Res 51: 3062-3066.

11. Ran S, Downes A, Thorpe PE (2002) Increased exposure of anionic phospholipids on the surface of tumor blood vessels. Cancer Res 62: 6132-6140.

12. Murayama T, Zuber C, Seelentag W K, Li WP, Kemmner W, et al. (1997) Colon carcinoma glycoproteins carrying alpha 2,6-linked sialic acid reactive with Sambucus nigra agglutinin are not constitutively expressed in normal human colon mucosa and are distinct from sialyl-Tn antigen. Int J Cancer 70: 575-581.

13. Sebzda T, Saleh Y, Gburek J, Warwas M, Andrzejak R, et al. (2006) Total and lipid-bound plasma sialic acid as diagnostic markers in colorectal cancer patients: correlation with cathepsin B expression in progression to Dukes stage. J Exp Ther Oncol 5: 223-229.

14. Kwak DH, Ryu JS, Kim CH, Ko K, Ma JY, et al. (2011) Relationship between ganglioside expression and anti-cancer effects of the monoclonal antibody against epithelial cell adhesion molecule in colon cancer. Exp Mol Med 43: 693-701.

15. Ueoka R, Matsumoto Y, Moss RA, Swarup S, Sugii A, et al. (1988) Membrane matrix for the hydrolysis of amino acid esters with marked enantioselectivity. J Am Chem Soc 110: 1588-1595.

16. Kitamura I, Kochi M, Matsumoto Y, Ueoka R, Kuratsu J, et al. (1996) Intrathecal chemotherapy with 1,3-bis(2-chloroethyl)-1-nitrosourea encapsulated into hybrid liposomes for meningeal gliomatosis: an experimental study. Cancer Res 56: 3986-3992.

17. Matsumoto Y, Kato T, Iseki S, Suzuki H, Nakano K, et al. (1999) Remarkably enhanced inhibitory effects of hybrid liposomes on the growth of specific tumor cells. Bioorg Med Chem Lett 9: 1937-1940.

18. Komizu Y, Matsumoto Y, Ueoka R (2006) Membrane targeted chemotherapy with hybrid liposomes for colon tumor cells leading to apoptosis. Bioorg Med Chem Lett 16: 6131-6134.

19. Nagami H, Nakano K, Ichihara H, Matsumoto Y, Ueoka R (2006) Two methylene groups in phospholipids distinguish between apoptosis and necrosis for tumor cells. Bioorg Med Chem Lett 16: 782-785.

20. Matsumoto Y, Iwamoto Y, Matsushita T, Ueoka R (2005) Novel mechanism of hybrid liposomes-induced apoptosis in human tumor cells. Int J Cancer 115: 377-382. 
Citation: Ichihara H, Motomura M, Matsumoto Y (2016) Negatively Charged Cell Membranes-Targeted Highly Selective Chemotherapy with Cationic Hybrid Liposomes against Colorectal Cancer In Vitro and In Vivo. J Carcinog Mutagen 7: 267. doi:10.4172/2157-2518.1000267

Page 8 of 8

21. Nagami H, Matsumoto Y, Ueoka R (2006) Chemotherapy with hybrid liposomes for lymphoma without drugs in vivo. Int J Pharm 315: 167-172.

22. Ichihara H, Nagami H, Kiyokawa T, Matsumoto Y, Ueoka R (2008) Chemotherapy using hybrid liposomes along with induction of apoptosis. Anticancer Res 28: 1187-1195.

23. Umebayashi M, Makizono T, Ichihara H, Matsumoto Y, Ueoka R (2010) Inhibitory effects of cationic hybrid liposomes on the growth of human renal cell carcinoma. Anticancer Res 30: 327-337.

24. Schröder-Borm H, Bakalova R, Andrä J (2005) The NK-lysin derived peptide NK-2 preferentially kills cancer cells with increased surface levels of negatively charged phosphatidylserine. FEBS Lett 579: 6128-6134.

25. Harder T, Scheiffele P, Verkade P, Simons K (1998) Lipid domain structure of the plasma membrane revealed by patching of membrane components. J Cell Biol 141: 929-942.

26. Matsumoto Y, Cao E, Ueoka R (2013) Growth inhibition by novel liposomes including trehalose surfactant against hepatocarcinoma cells along with apoptosis. Anticancer Res 33: 4727-4740.
27. Hondroulis E, Zhang R, Zhang C, Chen C, Ino K, et al. (2014) Immuno nanoparticles integrated electrical control of targeted cancer cell development using whole cell bioelectronic device. Theranostics 4: 919-930.

28. Sharma G, Modgil A, Layek B, Arora K, Sun C, et al. (2013) Cell penetrating peptide tethered bi-ligand liposomes for delivery to brain in vivo: Biodistribution and transfection. J Control Release 167: 1-10.

29. Shimoda S, Ichihara H, Matsumoto Y, Ueoka R (2009) Chemotherapy with hybrid liposomes for human breast tumors along with apoptosis in vivo. Int J Pharm 372: 162-168.

30. Martin FJ, MacDonald RC (1976) Lipid vesicle-cell interactions. I. Hemagglutination and hemolysis. J Cell Biol 70: 494-505.

31. Stoll C, Holovati JL, Acker JP, Wolkers WF (2012) Synergistic effects of liposomes, trehalose, and hydroxyethyl starch for cryopreservation of human erythrocytes. Biotechnol Prog 28: 364-371. 